\title{
Open Fracture of Neck of Metacarpal Bone
}

National Cancer Institute

\section{Source}

National Cancer Institute. Open Fracture of Neck of Metacarpal Bone. NCI Thesaurus.

Code C35358.

A traumatic break in the area of the metacarpal bone located between the diaphysis and the distal metaphysis that involves a break in the adjacent skin. 